\title{
Memories of 100 years of human fear conditioning research and expectations for its future
}

\author{
Bram Vervliet ${ }^{1,2} \&$ Yannick Boddez ${ }^{3,4}$ \\ ${ }^{1}$ Department of Brain and Cognition, KU Leuven \\ ${ }^{2}$ Leuven Brain Institute, KU Leuven \\ ${ }^{3}$ Department of Experimental Clinical and Health Psychology, Ghent University, Ghent, \\ Belgium \\ ${ }^{4}$ Center for the Psychology of Learning and Experimental Psychopathology, KU Leuven, \\ Leuven, Belgium
}

Author note: Bram Vervliet and Yannick Boddez contributed equally. Correspondence concerning this article should be addressed to Bram Vervliet or Yannick Boddez. Email: bram.vervliet@kuleuven.be or yannick.boddez@ugent.be. Yannick Boddez is supported by Ghent University grant BOF16/MET_V/002 awarded to Jan De Houwer. 


\section{Table of Contents}

1. How Little Albert became afraid of rats

2. Conditioned emotional reactions

3. John B. Watson's theory of emotions

4. The behavioral neuroscientist inside John B. Watson

5. Post-Watsonian developments in human fear conditioning

6. Standing on the shoulders of giants

7. Meanings of the term 'human fear conditioning model'

8. Testing the link between model and suffering outside the laboratory

9. Long live the human fear conditioning model! 


\begin{abstract}
This special issue celebrates the $100^{\text {th }}$ anniversary of the Little Albert study, published in February 1920, which marked the birth of human fear conditioning research. The collection of papers in this special issue provides a snapshot of the thriving state of this field today. In this Editorial, we first trace the historical roots of the field and then provide a conceptual analysis of the many ways in which human fear conditioning is currently used in theory and treatment development, with special reference to the contributions in this special issue. Ivan P. Pavlov allegedly claimed that "If you want new ideas, read old books". We could not agree more; it is our conviction that tracing the roots of our field illuminates current trends and will contribute to shaping new directions for the next 100 years of research.
\end{abstract}


The Little Albert study was the first fear conditioning experiment ever conducted on a human subject. As we will show below, this single experiment with one single subject and only crude measurements pioneered the principles of experimental psychopathology and behavior therapy. It would take several more decades before these two domains got traction, but the core principles were already spelled out in a series of papers in the 1910s and 1920s by John Broadus Watson, lead author of the Little Albert study. He also had an enormous impact on experimental psychology by convincing his fellow researchers to change their methods and goals, and he laid the ground for laboratory-based applied psychology at the same time. Elements of his approach to psychology, which he coined Behaviorism, are still mainstream today, even though many psychologists would hesitate or downward refuse to identify as such. But anyone who practices experimental psychology or exposure treatment is following the footsteps of John B. Watson. This includes researchers who focus on brain mechanisms. We will substantiate these assertions below, but let's have a closer look first at the study that changed the face of psychology.

\section{How Albert became afraid of rats}

A toddler named Albert showed no sign of fear when confronted with a range of stimuli, including a rat, a rabbit, a fur coat or even a burning newspaper. One of the few things that upset little Albert was a loud clanging noise. John B. Watson and Rosalie Rayner took advantage of these differences in emotional reactivity to test the possibility of conditioning emotional reactions. In order to do so, they put the rat in front of Albert and then produced the clanging noise by striking a hammer on a suspended steel bar.

The first experimental session contained two pairings of the rat and the loud noise. One week later, Albert showed some sign of fear when exposed to the rat alone ("...no tendency at first to reach for it”, Watson \& Rayner, 1920, p. 4). After five more pairings in that session, exposure to the rat alone elicited a strong fear reaction, as indicated in the experimental notes: "The instant the rat was shown the baby began to cry. Almost instantly he turned sharply to the 
left, fell over on left side, raised himself on all fours and began to crawl away so rapidly that he was caught with difficulty before reaching the edge of the table" (Watson \& Rayner, 1920, p. 5). When presented with toy blocks, on the other hand, Albert was calm and interacted in a playful manner. This indicated that the loud clanging noise did not induce a chronic anxious state in Albert. His newly learned fear was specific to the rat, or so it seemed.

Watson and Rayner hypothesized that the conditional fear reactions would extend beyond the conditional stimulus (the rat). ${ }^{1}$ They investigated this hypothesis by employing a generalization test procedure, in which, after five days, they exposed Albert to the range of stimuli from the pre-conditioning baseline measurement (rabbit, fur coat, etc.). Most stimuli now also elicited the fear reactions. A repetition of the same test 5 days later yielded similar results. Immediately after the last test, the dog and the rabbit were paired with the loud noise for the first time, followed by another round of generalization tests in a different context (a welllit lecture room, instead of the dimmed room of the laboratory). In this new context, the fear reactions were weaker but still noticeable to the original and the new conditional stimuli. Follow-up tests after one month still showed signs of fear to the rat and the other stimuli. Watson and Rayner concluded (p. 12; italics added): “These experiments would seem to show conclusively that directly conditioned emotional responses as well as those conditioned by transfer persist, although with a certain loss in the intensity of the reaction, for a longer period than one month. Our view is that they persist and modify personality throughout life."

Given that the newly conditioned fear did not disappear by itself, Watson and Rayner advocated the need for active methods that could remove such fear. They were all set to test out a number of methods, but Albert was adopted and left the hospital before they could carry out the envisioned experiments. In the Discussion section of the 1920 paper, they generously gave away their ideas for such methods, including (1) repeated exposures to the rat, (2) pairing the rat with positive rewards, (3) stimulating approach behaviors towards the rat, and (4) modeling 
non-fearful interactions with the rat. It does not take much to recognize the key ingredients of modern-day cognitive behavioral therapy for reducing fear and anxiety. In addition, and as illustrated in this special issue, these proposed methods continue to rank among the most popular topics in the field of human fear conditioning (extinction, counterconditioning, approach-avoidance, social learning).

A few years later, Watson was able to test the proposed methods in collaboration with Mary Cover-Jones, who had graduated from Vassar College, Baltimore, the same year as Rosalie Rayner, Watson's co-author on the Little Albert study. Upon Rayner's recommendation, Mary Cover Jones had attended a weekend lecture by Watson at Columbia University, New York, in 1919, after which she decided to embark on graduate studies in psychology with the aim of testing the proposed methods to eliminate fears in children. The results appeared in two papers in 1924 (Jones, 1924a,b), one of them reporting the case of Little Peter who had very similar fears as those installed in Little Albert. With great eye for detail and systematicity, she tested the different methods and recorded behavioral indices of Peter's progress during these exposure sessions. Counterconditioning proved to be the most efficient technique in this case. Interestingly, she also reported a case of reinstatement avant la lettre when Peter's fear of rats returned after he had been attacked by a dog (as indicated by point $b$ on the graph on p. 465 and clarified in the main text on p. 466; Jones, 1924a).

The translational ambition of the field of human fear conditioning is rooted in these two seminal studies on Little Albert and Little Peter. The Little Albert study effectively translated the principles of Pavlovian conditioning from salivary reflexes in dogs to emotional reactions in a human child. Such cross-species translation was regarded by Watson as one of the core goals of psychology: "The man and the animal should be placed as nearly as possible under the same experimental conditions" (Watson, 1913, p. 252). This approach is still followed in many studies today that test hypotheses from the rodent laboratory in human fear conditioning. The 
Little Peter study, on the other hand, provided an early example of lab-to-clinic translation in which principles from the laboratory are tested in an applied setting with the aim of optimizing evidence-based treatment. To Watson, treatment is applied experimental psychology, and clinicians are practitioners of scientific principles.

The Little Albert study and Watson's views foreshadowed experimental psychopathology as a field of psychological research: “[The psychiatrist's] interest is largely in the patient and need not be particularly scientific. The psychologist, on the other hand, cannot afford to rest until he controls his phenomena - until he can not only produce [maladaptive responses] and study the laws of their production, but also reduce and break them up at will and learn the principles controlling their reduction. He must find a uniform procedure which will allow at least approximate reproducibility of his results. In general, he must have his phenomena under such control that he can watch their inception, course, and end." (Watson \& Morgan, 1917, p. 168, italics added).

It is almost incredible that one single experiment with a sole participant was so groundbreaking in the light of contemporary approaches to clinical treatment and translational research. And there was even more than that: The Little Albert study ${ }^{2}$ also had widespread theoretical implications.

\section{Conditioned emotional reactions.}

It is interesting that Watson and Rayner did not title their 1920 article "The case of Little Albert" or "A laboratory model of fear". Instead, they chose "Conditioned emotional reactions". This title may ordinarily not catch much attention, but it was spot on.

At the time, the field of psychology was dominated by the Wundtian method of introspection. This method relied on subjects trained in the introspective method to observe and report their own conscious reactions to external situations. A study consisted, for example, of trained subjects viewing pictures of different shades of grey and reporting how these elicited 
isolable sensation attributes, such as quality, extension, duration, intensity, clearness etc. (see Watson, 1913 , p. 249-250). Watson criticized this method on three grounds. First, he did not agree that experimental psychology should aim for analyzing conscious states into introspectively isolable elements. Rather, he asserted, "Its theoretical goal is the prediction and control of behavior" (Watson, 1913, p. 248). The relevance of psychology to other scientific fields and society will not come from endlessly introspecting one's own conscious impressions. Instead, it will require identifying the variables that reliably predict and control behavior. By conditioning emotional reactions, Watson showed how even the most intimate phenomena, our emotions, are subject to environmental control. Moreover, this approach shed light on the mechanism that brings about these emotions, rather than providing a sheer endless inventory of their appearances.

Watson's second critique to the method of introspection was that replications were practically impossible. Differences in results between identical experiments could always be due to differences in mastery of the introspective method by the trained subjects in one's laboratory. Or, as Watson puts it: "If you fail to reproduce my findings, it is not due to some fault in your apparatus or in the control of your stimulus, but it is due to the fact that your introspection is untrained... The attack is made upon the observer and not upon the experimental setting." (Watson, 1913, p. 249). By relying on objectively observable behaviors, on the other hand, the replicability of the conditioning of emotional reactions is testable: "Psychology as the behaviorist views it is a purely objective experimental branch of natural science" (Watson, 1913, p. 248).

The third critique of Watson had to do with the relevance of psychology as a scientific and applied discipline. Who cares about subjective conscious impressions of a trained subject who is viewing shades of grey? Outside of the Wundtian laboratory, so claims Watson, practically nobody. "The psychologist is being constantly asked by his own students as well as 
by the physicians, educators, and jurists: "Why do you not work upon the emotions? They are of more importance in the guidance and control of the human organism than any of your hairsplitting work upon thresholds." (Watson \& Morgan, 1917, p. 164). By studying conditional emotional reactions, he hoped to increase the influence of psychology in science and society. "If psychology would follow the plan I suggest, the educator, the physician, the jurist and the businessman could utilize our data in a practical way, as soon as we are able, experimentally, to obtain them." (Watson, 1913, p. 251).

\section{John B. Watson's theory of emotions}

The Little Albert study pioneered the field of experimental psychopathology and challenged the introspectionists, but it also served to contrast different theories of emotion. Watson and Morgan (1917) outlined the different perspectives on emotion that existed at the time. It had become mainstream since the work of Charles Darwin that we share emotional expressions with many other species and that even our emotions may have developed via the principles of natural selection (Darwin, 1872). Watson and others believed that at least some basic emotions must be inherited to a certain degree, but the question remained as to how many basic emotions we are born with. Two different psychological approaches existed at the time with regard to the problem of emotion.

Edward Thorndike proposed that most of our emotions are inherited. He went at great lengths to analyze all possible human emotions and to enumerate with painstaking detail the stimulus-response associations that characterize these emotions (Thorndike, 1913). Watson applauded this effort of systematically analyzing human emotions but doubted whether they are all inherited. After observing hundreds of infants in his own laboratory (Watson \& Rayner, 1921), Watson came to a different conclusion: "We have reason to think that very many of the reactions which Thorndike puts down as original in the nature of the infant are undoubtedly the product of the environment" (Watson \& Morgan, 1917, p. 165). He also questioned the 
methodological approach of Thorndike: "Depending blindly upon the fact that emotional reactions are hereditary, we have put emphasis on trying to enumerate the hundreds of objects and situations which produce the hundred or so of emotional reactions, instead of taking emotions as we find them and trying to put them under experimental control" (Watson \& Morgan, 1917, p. 168). A true psychological understanding of emotions, according to Watson, rests on the ability to predict and control these emotions.

Sigmund Freud took an approach that was opposite to Thorndike's. Freud provided a very parsimonious account of emotions, but too narrow in Watson's eyes (Watson \& Morgan, 1917). Freud's theory highlights the primacy of only one basic emotion, namely sex (rephrased by Watson as 'love'; current terminology would be 'desire'). All the other emotions would then later be derived from this one basic emotion (e.g., fear may derive from an apprehension that a loved one might disappear). In his own systematic analysis of infant behaviors, Watson observed more emotional expressions and took issue with the sole emphasis on the emotion of sex. In addition, the Little Albert study proved that fears can develop through mere pairings of a neutral stimulus with an aversive stimulus. "Fear does not gather its potency in any derived manner from love. It belongs to the original and inherited nature of man" (Watson \& Rayner, 1920, p. 14). They further attacked the psychoanalytic method with an ironic prophecy: "The Freudians twenty years from now... when they come to analyze Albert's fear of a seal skin coat... will probably tease from him the recital of a dream which upon their analysis will show that Albert at three years of age attempted to play with the pubic hair of the mother and was scolded violently for it. (We are by no means denying that this might in some other case condition it.)" (Watson \& Rayner, 1920, p. 14).

Watson took position somewhere in between Thorndike and Freud. Based on observations of hundreds of infants in his own lab, he claimed the primacy of three basic emotions in the infant from which all emotions in adult-life are derived: fear, love and rage. 
But, "It may be argued that if these three emotional reactions are the important ones and that if the stimuli which call them out are as simple and crude as we now suppose them to be, then our theory of the emotions is superficial and patently unable to care for the enormous complexity in the shading of emotional reactions in adults." (Watson \& Morgan, 1917, p. 168). He believed to have found the answer in the mechanism of Pavlovian conditioning. He came to believe that through conditioning an increasing number of stimuli triggers these emotions and that through conditioning-by-transfer (generalization) the various emotions combine and interact in an everwidening array of stimuli that shape the rich variety of emotional experiences.

The Little Albert study challenged Freud's hypothesis that the emotion of fear is merely derived from sex and it also challenged Thorndike's hypothesis that most adult-life emotions are inherited. In Watson's eyes, the mechanism of Pavlovian conditioning (plus transfer/generalization) was sufficient to explain the development of all adult-life emotions from a parsimonious set of three inherited emotions: fear, love and rage. This crude theory of emotion is obviously outdated, and the concept of basic emptions has since been questioned (Lange, Dalege, Borsboom, van Kleef, \& Fischer, 2020), but it did provide an important step forward at the time. This further demonstrates the pervasive implications of this single study with a sole participant for multiple directions of psychological inquiry.

\section{The behavioral neuroscientist inside John B. Watson}

Watson had a prime interest in animal and human biology. The term 'Behaviorism' seems to suggest that he only cared for studying the laws between external stimuli and reactions, but this is not entirely true. The emphasis was indeed on psychology as a branch of the natural sciences, and on the use of experimental methodology to predict and control behavior. But his interest also extended to the inner biological structures that make behavior possible, such as the functional anatomy of muscles, glands and the central nervous system. Human biology featured prominently in his book Behaviorism (Watson, 1924), a collection of introductory lectures to 
behaviorist psychology, where he devoted two entire chapters to it. He embraced biological mechanisms as far as they contributed to an understanding of behavior. Even in his own laboratory, during initial attempts to set up human conditioning techniques, he applied a variety of psychophysiological measurements, such as the psycho-galvanic reflex (akin to the skin conductance response), the pupillary reflex, respiratory reflex (breathing volumetric parameters), and heartbeat (Watson, 1916).

Watson welcomed contributions from biology to the understanding of behavior, but he was also wary of an overly narrow emphasis on the central nervous system: "Should we as behaviorists be especially interested in the central nervous system?” (Watson, 1924, p. 43). He argued that the central nervous system is not more important in the production of behavior than muscles or glands. It is just one of the many parts of the whole organism that make behavior possible: "For the behaviorist the nervous system is, $1^{\text {st }}$, a part of the body—no more mysterious than muscles and glands; $2^{\text {nd }}$, it is a specialized body mechanism that enables its possessor to react more quickly and in a more integrated way with muscles or glands when acted upon by a given stimulus than would be the case if no nervous system were present" (Watson, 1924, p. 43). There are many species without a central nervous system that adjust their behavior adaptively to their environment. This is all behavior, up and down the evolutionary scale. Watson agrees that the central nervous system makes more complex patterns of behavior possible, but this is not more essential to the understanding of behavior than muscles and glands.

This bold argument served to further separate the behaviorist from the introspectionist view. "To understand why it hurts the feelings of the introspectionist for the behaviorist to place no more emphasis on the brain and the spinal cord than upon the striped muscles of the body, the plain muscles of the stomach, the glands etc., you must remember that the nervous system to the introspectionist has always been a mystery box-whatever he couldn't explain in 'mental' terms he pushed over into the brain. Many of our so-called physiological psychologies 
are filled with pretty pictures of brain and spinal cord schemes." (Watson, 1924, p. 43, italics added). Could this be more relevant today? In recent years, there has been increasing acknowledgement that the seductive allure of colorful images of brain activations can stand in the way of rigorous science (Beck, 2010; Hopkins, Weisberg, \& Taylor, 2016; Weisberg, Keil, Goodstein, Rawson, \& Gray, 2008). The introspectionist's trap may have opened once again. Given that a single pattern brain activity will always be compatible with multiple psychological theories, psychological interpretations of fMRI-based brain activations are necessarily speculative. Still, they are the rule rather than the exception. This threatens to weaken psychology, and ultimately neuroscience as well: Neuroscience needs rigorous behavioral experimentation (Krakauer, Ghazanfar, Gomez-Marin, MacIver, \& Poeppel, 2017).

Of course, there are very good arguments for focusing on the brain, where most neural plasticity occurs. But Watson reminds us that the brain does not live in a vacuum. It is one of many parts that mediate between stimulus input and response output. Therefore, “... the behaviorist has to be vitally interested in the nervous system but only as an integral part of the whole body" (Watson, 1924, p. 43).

\section{Post-Watsonian developments in human fear conditioning}

Soon after publication of the Little Albert study, clinical case reports confirmed that phobias can be traced back to aversive conditioning experiences (Bagby, 1922; Anderson, 1927). It is good to repeat here that this was diametrically opposite to the dominant Freudian view at the time, which claimed that symptoms of anxiety (including phobic symptoms) result from repressed sexual desires. Treatments focused on these underlying sexual desires and their repression, rather than on the fear itself. The new approach claimed that problems of fear were, well, problems of fear, and should be treated as such.

In the fear conditioning laboratory, the first developments focused on replicating the Little Albert study (Moss, 1924; English, 1929; Bregman, 1934, Jones, 1930). Most of the work 
was done by Harrold E. Jones, husband of Mary C. Jones and assistant professor at Columbia University. He perfected the methods used by Watson in many ways. To the positivist Jones, the use of observer's reports to infer emotional reactions was still insufficient for a truly objective investigation of human fear conditioning. He presented his first results at the $36^{\text {th }}$ annual symposium of APA in 1927, titled "Conditioned Psychogalvanic Responses in Infants". In three infants, he paired previously indifferent stimuli (cutaneous, auditory, and visual) with electrical stimulation of the skin and consistently observed increased psychogalvanic responses (akin to the skin conductance reaction). Jones noted that “... the overt behavior of the infants showed no correlated effects; the evidence for conditioning was derived entirely from the instrumental records" (Jones, 1928, p. 184). In a follow-up study, he further included a neutral stimulus that was equally often presented but never paired with the electrical stimulation, as a baseline comparison for the conditional psychogalvanic response (Jones, 1931). Differential conditioning, aversive electrical stimulation, skin conductance recording: The human fear conditioning laboratory was born!

During the 1930s, the emphasis shifted from the clinical-translational and emotional angle towards the cross-species translation of basic principles of classical conditioning to human subjects. A factor in this is that Pavlov's complete work had recently become accessible with the publication of a full English translation of his book Conditioned Reflexes (Pavlov, 1927). Before that, only the basics of Pavlov's work were accessible, including to Watson, in one translated lecture published in The Lancet (Pavlov, 1906). Bass \& Hull (1934) took the lead with the study of conditional fear generalization ("irradiation") by reproducing as closely as possible a generalization experiment from Pavlov's laboratory in which spatial distance between tactile stimulations served as the similarity dimension. Subjects were naked and laid face-down on a bench. A tactile stimulation over the shoulder was followed by an intense electric stimulation to the wrist. During test, more distant tactile stimulations on the subject's 
back toward the calf triggered progressively weaker psychogalvanic responses, resulting in the typical shape of the gradient. Bass and Hull went on to characterize the generalization gradient of extinction as well. But they duly noted some obstacles with their newly developed procedure: "Several men declined to act as subjects because they objected either to being shocked or to the removal of their clothing" (Bass \& Hull, 1934, p. 54).

The 1930s became the decade of generalization. Most notably, Carl I. Hovland published a series of four papers with systematical investigations of the generalization gradient in auditory conditioning (Hovland, 1937a-d). He manipulated factors like tone frequencies and intensities, differential conditioning, reinforcement rate, extinction training, lapse of time, etc. The results refuted Pavlov's cortical irradiation theory of generalization (Pavlov, 1927). According to this theory, the degree of generalization between two stimuli mirrors the cortical distance between their neural representations. Activation of one representation spreads ("irradiates") over the cortex and activates the other representation proportional to the distance travelled. The results of Bass and Hull (1934) previously confirmed this theory, because tactile stimulations of body parts are topographically organized in the somatosensory cortex: the cortical distance between shoulder and calf is larger than between shoulder and lower back. Tone frequencies are topographically organized in the primary auditory cortex and so the generalization gradient over tone frequencies was also in line with the irradiation hypothesis (Hovland, 1937a). But then Hovland demonstrated a similar gradient over tone intensities, which are not spatially distributed over the cortex (Hovland, 1937b). This disconfirmed the irradiation hypothesis and inspired novel conceptualizations of the generalization process (Hull, 1947; Lashley \& Wade, 1946).

Hovland (1937c) also investigated extinction and recovery of conditional psychogalvanic responses. One of his experiments was aimed to test 'disinhibition' in humans. This phenomenon, once again first described by Pavlov (1927), referred to the observation that 
addition of a neutral stimulus to a conditioned-and-extinguished stimulus triggers a return of the conditional response (see also Switzer, 1933). As the additional neutral stimulus, Hovland switched off the houselights and indeed observed a return of the psychogalvanic response. To the extent that light/dark changes can be considered contextual changes (Vansteenwegen et al., 2005), this report represents the first demonstration of contextual renewal (AAB-renewal specifically). Learning theorists at the time explained extinction in terms of inhibition learning, which could be easily disturbed by the lapse of time or changes in the external situation (like the addition of a neutral stimulus; Pavlov, 1927; Hull, 1943). These ideas are still engrained in the currently dominant view on fear extinction learning and retention (Bouton, 2002).

It is interesting to see that many of the processes under investigation today were already at the forefront in Watson's pioneering work and in the ensuing wave of human fear conditioning researchers (extinction, generalization, recovery...). There are more examples, like Cook and Harris (1937) who reported that instructing subjects that a green light would be followed by an electrical stimulation immediately elicited increased psychogalvanic response on the first presentation of the green light. Likewise, instructing the absence of further stimulations after actual light—shock pairings abolished the conditional response immediately. Such demonstrations of instructed conditioning and instructed extinction generated great interest in recent years (Mertens, Boddez, Sevenster, Engelhard, \& De Houwer, 2018).

But it's equally interesting to note what was not on the research agenda in those days: individual differences. The field was geared towards translating and testing the basic principles from Pavlov's laboratory to the human case. The goal was to reveal universal laws of learning: how we are all alike, not how we all differ. Nonetheless, Pavlov himself did have a keen interest in individual differences. He even developed a temperamental typology of his dogs, as a proxy for distinct central nervous system organizations, and documented how these influenced the course of conditioning (Pavlov, 1927). This aspect of Pavlov's work has been taken up more 
recently, with a surge of interest in individual differences in human fear conditioning, paralleled by a modal shift towards personalization in biomedical research and an increased emphasis on the individual in the humanities and society as a whole.

\section{Standing on the shoulders of giants}

One hundred years after the development of the human fear conditioning procedure, the number of research lines and publications today is unprecedented. On top of what we discussed above, additional seeds for this wealth were planted in the 1960s, 1970s and 1980s. Arguably, however, the field really took off in the late 1990s, when novel developments in the animal laboratory met with clinical interest. On the one hand, the seminal work of Mark Bouton on the extinction and recovery of fear, and his relentless argumentation for its clinical applicability, paved the way for a clinical translational research agenda centered around extinction (Bouton, 2002). On the other hand, the work of Joseph LeDoux on neural processes of fear conditioning in rats (LeDoux, 2003) and the advent of functional neuroimaging techniques (MRI) in humans ignited experimental validation of cross-species translation to the human case. The Bouton and LeDoux lines came together in the early 2000s with the work of Gregory Quirk, Elisabeth Phelps and others, which spurred an investigation into the behavioral and neural processes of the extinction and return of fear (Milad \& Quirk, 2012). Findings that pharmacological adjuncts can strengthen the cellular process of fear extinction and boost long-term extinction retention further bolstered attention in this area (Singewald, Schmuckermair, Whittle, Holmes, \& Ressler, 2015). Fascination also emerged concerning reports that administration of pharmacological agents before or after presenting a fear-conditioned stimulus can reduce fear responding and its return in the absence of further extinction training (i.e., reconsolidation interference techniques; Beckers \& Kindt, 2017). Although some of the initial enthusiasm has waned after a couple of failed replications (Chalkia et al., 2020; Chalkia, Weermeyer, Van 
Oudenhove \& Beckers, 2019), the hopes remain that innovative laboratory developments will one day improve current treatments for psychological suffering.

The contemporary field of human fear conditioning has diversified beyond extinction and reconsolidation research alone. With this special issue, we take a snapshot of the many different research topics that are being covered today. Despite their variety, all contributing articles have one thing in common: The human fear conditioning model that was developed in embryonic form by Watson and confederates a century ago. Each contributing article uses this fear conditioning model from a unique and often inter-disciplinary angle. This testifies to the strength of the model at the intersection of many different research interests, but this intersectional position may also invoke the danger of losing conceptual clarity. What do contemporary researchers mean when they talk about the fear conditioning model? This is not always clear. Below, we analyze the different uses of this term in the literature, because we believe that conceptual clarity is essential for future progress. Along the way, we refer to the contributions to the current special issue in italics.

\section{Meanings of the term 'human fear conditioning model'}

The terms that we use to describe our research endeavors may influence our thinking about the processes involved. For example, when we apply an 'attention task' in our experiments, we are prone to interpreting any result in terms of attentional processes. In our papers, we often use the term 'human fear conditioning model' to describe the type of experiments that we conduct. However, there are many meanings that go under that umbrella term. A clear view on those meanings may contribute to a precise interpretation of our research findings.

\subsection{A model as a procedure that models something else}

Human fear conditioning is first and foremost a procedure. In general terms, a procedure is what a researcher does when carrying out an experiment (De Houwer \& Hughes, 2020). In the case of fear conditioning, this entails - very much in the tradition of Watson and his successor 
Jones - presenting aversive stimulus pairings and assessing changes in fear-related responding. It is important to delineate the hypothesized process in a model from its procedure. This is why the Pavlovian conditioning model is still relevant today: Even though some early hypotheses about processes have been discarded (including Pavlov's theory; 1927), the procedure lives on.

A procedure becomes a model in the true meaning of the word if researchers assume that it models or provides an analogy for something else (i.e., the target phenomenon; Weisberg, 2013). The use of laboratory models is omnipresent in science. For example, in biomedical sciences, synthetic ion channels are sometimes used as a model of natural ion channels, as this facilitates aspects of the research process (Chen \& Hou, 2018). In the case of human fear conditioning, the target phenomenon often concerns psychological suffering as seen in anxietyand stress-related disorders (sometimes as part of other forms of suffering such as chronic pain; Meulders, this issue). As with any model, this begs the question to what extent findings obtained with the model are informative with respect to the target phenomenon. When we study human fear conditioning in the laboratory, do we only learn about the behavior and (neural) processes that occur within the limits of that procedure, or do we also learn something about psychological suffering in the world outside the laboratory? This issue of external validity is so critical to the field of human fear conditioning that several contributions in the special issue touch upon it (Bach \& Melinscak, this issue; De Houwer, this issue; Fullana et al, this issue; Hammel, Helwig, Kaczkurkin, Sponheim, \& Lissek, this issue; Pölchen et al., this issue). We will cover this matter in more detail in section 8.

\subsection{A model as a hypothesis about the cause of behavior}

The term fear conditioning model is sometimes used to refer to a theory (the hypothesized process) rather than to a procedure. In this sense, the fear conditioning model holds that anxiety, trauma- and stress-related complaints in the population are conditioning effects (at least for a subset of sufferers; Rachman, 1977), meaning that they result from a previous pairing of stimuli 
(De Houwer, this issue; Vervliet \& Boddez, 2020). Once again, the influence of Watson is clear in this.

Most researchers also invoke a specific mental mechanism when they use the term fear conditioning model in this sense. For example, according to one influential view, invoking the fear conditioning model implies invoking a mental landscape that consists of associations between stimulus representations (for a critical discussion of association formation models and alternative views see De Houwer, this issue). Associations can be defined as links that transmit activation from one representation to another, which may remind us of the way in which a strip of copper wire conducts electricity (Haselgrove, 2016; Mitchell, De Houwer, \& Lovibond, 2009). Representations often remain undefined but can be understood as mental imprints, comparable to physical imprints (e.g., a neon sign or a drawing in clay; Holland, 1993; Skinner, 1977). So, the idea here is that presentation of the conditional stimulus activates both its own mental representation and that of the unconditional stimulus, which (via some unspecified way) then leads to fear. The simplicity of the association formation model may be what makes it so attractive. A risk, however, is that researchers may treat associative activation as a blank canvas on which they project a variety of actually incompatible constructs. For example, associative activation has been treated as equivalent with both expectancies concerning future events and memories of past events, which seems contradictory (for an extensive discussion, see Jozefowiez, 2018). In other words, researchers may expect more of associations as compared to what the construct sensu stricto allows ${ }^{3}$.

\section{Testing the link between model and suffering outside the laboratory}

We have seen that the term fear conditioning model is on some occasions used to refer to a laboratory procedure that aims to model (i.e., simulate) psychological suffering as seen in anxiety- and stress-related disorders, while on other occasions used to refer to more or less specified hypotheses about the origin of such suffering in the population. The study of 
moderators of the relation between stimulus pairings and behavioral changes (i.e., of conditioning effects) is crucial to assess the value of the fear conditioning model in both meanings of the term.

First, with respect to the value of the laboratory procedure, it is of the essence to assess whether what moderates performance in the laboratory also moderates anxiety- and stressrelated complaints in the world outside the laboratory. If so, then this supports the external validity of the model (i.e., what is learned from the model extends to the target phenomenon) and we can rest assured that we can continue to invest in fear conditioning research (see De Houwer, this issue; Scheveneels, Boddez, \& Hermans, 2019; Vervliet \& Raes, 2013). The idea here is that a higher number of moderators that show parallel effects in the model and for the target phenomenon will increase the chance that a new and untested factor will also show parallel effects (e.g., a new intervention developed in the laboratory; see Keller, Hennings, \& Dunsmoor, this issue; Lipp, Waters, Luck, Ryan, \& Craske, this issue). This requires a research program that tests moderators in the model and of the target phenomenon, and that assesses overlap in the effects.

Second, with respect to theory development, accumulating knowledge about the moderating conditions under which stimulus pairings produce increased fear reactions, allows us to refine our theories about the pathways towards anxiety- and stress-related complaints in the world outside the laboratory. This will enable us to make (more) precise predictions about the onset and course of psychological suffering.

The last 100 years have seen a plethora of laboratory research on moderators, and several papers in this special issue carry on this important tradition. For example, the extent to which pairings of stimuli will result in fear responding may depend on characteristics of the stimuli, the behavior under investigation, and the participant (for a full taxonomy, see De 
Houwer \& Hughes, 2020). Below, we discuss these moderators and make humble suggestions for another 100 years of progress in human fear conditioning research.

\subsection{Stimulus characteristics}

Pavlov and Watson emphasized the importance of stimulus pairings as a prerequisite of conditioning but did not pay much attention to the characteristics of the stimuli involved. The last 100 years have shown that this is an oversight: Stimuli are key moderators of fear conditioning. The extent of the behavioral change due to stimulus pairings indeed depends on stimulus characteristics including the fear relevance of the conditional stimulus (e.g., flowers versus spiders; Öhman \& Mineka, 2001), the source of stimulation (e.g., interoception versus exteroception; see Meulders, this issue) and stimulus intensity (e.g., a strong versus mild unconditional stimulus; Dunsmoor, Kroes, Braren, \& Phelps, 2017).

With respect to the matter of external validity, the standard fear conditioning procedure has been criticized for relying on relatively simple stimulus material (e.g., geometrical figures as conditional stimuli) as compared to what may evoke fear in daily life (e.g., an audience in which some people are frowning). We do not deny that this might be the case, but we do oppose to an argumentation exclusively in terms of surface similarity. Whether or not stimuli in the model simply look like stimuli involved in the target phenomenon is not the crucial criterion. Models differ by definition from their target phenomenon (Weisberg, 2013). The crucial, and

essentially empirical, question is whether study results obtained with such simplified model still extend to the target phenomenon, or whether models with more complex stimuli would do a better job. In spite of the fact that Watson and his successors emphasized the translational potential of fear conditioning from the early days of the field, such empirical work is still surprisingly rare and urgently needed (Scheveneels, Boddez, Vervliet, and Hermans, 2016).

With respect to theory formation, the role of stimulus intensity has been incorporated in some models. For example, the Rescorla-Wagner model (1972) includes parameters that reflect 
the intensity of the conditional and unconditional stimulus. However, a model that fully accounts for all stimulus characteristics is currently still lacking.

\subsection{Response characteristics}

The extent of the behavioral change that is due to the stimulus pairings may also depend on the conditional response that is under investigation. In accord with the pioneering work of Harold Jones, typical measures include physiological responding (e.g., skin conductance; for a discussion and new analysis tool, see Bach \& Melinscak, this issue) and also ratings (e.g., USexpectancy ratings; Boddez, Baeyens, Luyten, Vansteenwegen, Hermans, \& Beckers, 2013). In addition, there is a resurgence of interest (Pittig, Wong, Glück, \& Boschet, this issue) in procedures that additionally allow participants to prevent the occurrence of the unconditional stimulus by means of a designated response (i.e., an avoidance response). Other measures are possible though. For example, one can measure whether the conditional stimulus comes to evoke a visual image of the unconditional stimulus (i.e., imagery or "conditioned seeing"; see Mertens, Krypotos, \& Engelhard, this issue) or include brain measures. Including multiple measures is of special theoretical interest in the case of response dissociations and in the case that responses form a causal network. We discuss both cases below.

Response dissociations (e.g., skin conductance versus US-expectancy; Bechara et al., 1995) provide a clear illustration of how the magnitude of the behavioral change due to stimulus pairings (i.e., of the conditioning effect) can depend on the behavior that is under investigation (i.e., moderation by response characteristics). Theories have so far almost exclusively focused on candidate mechanisms that drive the acquisition of information about stimulus relations in memory, but are surprisingly underdeveloped when it comes to accounting for the heterogeneity of conditional fear responding (i.e., the performance level; Honey, Dwyer, \& Iliescu, 2020; Miller, Barnet, \& Grahame, 1995). This is also illustrated by the fact that the terms 'fear memory' and 'fear responding' are sometimes used interchangeably, even though there are 
instances where remembering an aversive event and being fearful do not go hand in hand (for a detailed discussion see Boddez et al., 2020; Zenses, Baeyens, Beckers, \& Boddez, 2020). We see the development of a response account as a fundamental challenge for the future of our field. As such, we concur with Baeyens, Vansteenwegen, and Hermans (2009, p. 199) that a conditioning theory "that can explain all but conditioned behavior, is lacking something quintessential".

In the field of psychology at large, there is an increase in interest in network structures that detail relations among variables (Borsboom, Cramer, and Kalis, 2019). The general idea of this could be extended to conditional responses. In fact, evidence for causal networks of conditional responses is already starting to emerge. There is, for example, ongoing research on whether conditional changes in contingency judgments (sometimes termed "contingency awareness") cause conditional changes in physiology (Mertens \& Engelhard, 2020), on the conditional physiological responses that precede avoidance (Hunt, Cooper, Hartnell, \& Lissek, 2019; Pittig et al., this issue), and on the effect of the (pharmacological) manipulation of brain responses on conditional responses (Esser, Fuss, and Haaker, this issue). A thorough understanding of causal networks between responses is of theoretical interest, because a complete network could be considered a mechanistic theory that includes only observable events (to the researcher and / or to the participant; Skinner, 1953) and would be devoid of unobservable constructs (e.g., mental associations).

\subsection{Subject characteristics}

As noted in the section on post-Watsonian developments, the research community is highly invested in research about interindividual differences (e.g., in personality, age, sex, genetic makeup) in the extent to which stimulus pairings result in fear responding (i.e., differences in "trait conditionability"; Hammel et al., this issue; Klein, Shner, Ginat-Frolich, Vervliet, \& Shechner, this issue; Peyrot, Brouillard, Morand-Beaulieu, Marin, this issue; Pölchen et al., 
this issue). The idea is that - holding all other characteristics (e.g., stimulus intensities) equal some individuals will show more fear when confronted with stimulus pairings as compared to other individuals. This idea could serve as one candidate-explanation for why not everybody who is confronted with an aversive conditioning event goes on to develop anxiety-related complaints in real life (Mineka \& Zinbarg, 2006).

The research community fosters hope that individual differences in conditioning performance may eventually provide us with a premorbid marker of anxiety- and stress-related complaints. For this approach to be successful, it is required that the individual characteristics affect the level of responding in the fear conditioning procedure in the same way as how they affect the outcome (e.g., anxiety complaints) of being confronted with certain stimulus pairings outside the laboratory (e.g., being confronted with negative feedback after a presentation). In other words, this approach requires the absence of strong interactions between the individual characteristics and the other candidate moderators. For example, if individuals would only show stronger conditioning with a type of stimulus (e.g., critical feedback) or a type of behavior (e.g., negative thoughts) that is not modeled in the fear conditioning procedure, then successful prediction cannot be expected (also see Vervliet and Boddez, 2020). If this would turn out to be the case, then tailor-made models that do include the relevant stimuli and responses may come into the picture. Although tailor-made models (e.g., for social anxiety complaints; e.g., Blechert et al., 2015) may serve important research purposes (e.g., explaining and developing a treatment for such complaints), such models would have limitations as a premorbid marker, because they would necessarily angle for only a restricted range of complaints.

More generally, it may be worthwhile to consider the status of the outcomes that we aim to predict in fear conditioning studies on premorbid markers. DSM-like diagnoses and some of the often-used questionnaires may allow for too much heterogeneity in complaint profiles to be useful outcomes (or predictors for that matter; Borsboom et al., 2019) and are likely to be only 
distant proxies of the factors that do the causal work (e.g., prior learning history or goals; Moors, Boddez, and De Houwer, 2017). Indeed, it has been argued that science moves ahead by replacing concepts that lack a structural explanation (e.g. air has been rejected as a scientific concept because it is composed of different components such as oxygen, nitrogen, and carbonite; Moors, 2017).

Last but not least, heightened conditionability would only lead to suffering in real-life if the individual is additionally exposed to triggering stimulus pairings (e.g., critical feedback after a presentation; Mineka \& Zinbarg, 2006). However, as indicated above, current theories have little to say about what turns mere stimulus pairings - to which we are all constantly exposed - into stimulus pairings that support strong conditioning effects. As long as we lack precise ideas about which type of stimulus pairings are expected to trigger suffering, it will remain difficult to do a proper anamnesis in either research studies or clinical practice. Even in elegant prospective studies in which at-risk groups (e.g., soldiers or firemen) are followed over time (e.g., Lommen, Engelhard, Sijbrandij, van den Hout, and Hermans, 2013), there may be important differences in the characteristic of the stimulus pairings to which participants are exposed (e.g., was a soldier $10 \mathrm{~m}$ or $100 \mathrm{~m}$ removed from where the grenade struck?). In summary, there is a need for theories that allow for more precise predictions about individual differences in the onset and course of psychological suffering.

\section{Long live the human fear conditioning model!}

We have argued that, following the pioneering work of Watson, the human fear conditioning procedure provides us with a toolbox to study learning and emotion. Laboratory studies have revealed ample information about the conditions under which stimulus pairings result in fear responses and have fed discussion about the mechanisms that drive the acquisition of information about stimulus relations. Fear conditioning research is praised by some, but criticized by others, for its potential to inform clinical practice. We argued that this is essentially 
an empirical question and hope for a breakthrough on this issue as well as for new exciting research findings and insights during the next 100 years. The future starts today: We hope that the collection of excellent papers in this special issue will set the stage for this exciting endeavor. 


\section{References}

Anderson, J. E. (1927). The dream as a re-conditioning process. The Journal of Abnormal and Social Psychology, 22, 21-25.

THIS ISSUE: Bach, D. R., \& Melinscak, F. (2020). Psychophysiological modelling and the measurement of fear conditioning. Behaviour Research and Therapy.

Baeyens, F., Vansteenwegen, D., \& Hermans, D. (2009). Associative learning requires associations, not propositions. Behavioral and Brain Sciences, 32, 198-199.

Bagby, E. (1922). The etiology of phobias. The Journal of Abnormal Psychology and Social Psychology, 17, 16-18.

Bass, M. J., \& Hull, C. L. (1934). The irradiation of a tactile conditioned reflex in man. Journal of Comparative Psychology, 17, 47-65.

Bechara, A., Tranel, D., Damasio, H., Adolphs, R., Rockland, C., \& Damasio, A. R. (1995). Double dissociation of conditioning and declarative knowledge relative to the amygdala and hippocampus in humans. Science, 269, 1115-1118.

Beck, D. M. (2010). The appeal of the brain in the popular press. Perspectives on Psychological Science, 5(6), 762-766.

Beck, H. P., Levinson, S., \& Irons, G. (2009). Finding little Albert: A journey to John B. Watson's infant laboratory. American Psychologist, 64, 605-614.

Beckers, T., \& Kindt, M. (2017). Memory reconsolidation interference as an emerging treatment for emotional disorders: strengths, limitations, challenges, and opportunities. Annual Review of Clinical Psychology, 13, 99-121.

Blechert, J., Wilhelm, F. H., Williams, H., Braams, B. R., Jou, J., \& Gross, J. J. (2015). Reappraisal facilitates extinction in healthy and socially anxious individuals. Journal of behavior therapy and experimental psychiatry, 46, 141-150. 
Boddez, Y., Baeyens, F., Luyten, L., Vansteenwegen, D., Hermans, D., \& Beckers, T. (2013). Rating data are underrated: Validity of US expectancy in human fear conditioning. Journal of behavior therapy and experimental psychiatry, 44(2), 201-206.

Boddez, Y., Moors, A., Mertens, G., \& De Houwer, J. (2020). Tackling fear: Beyond associative memory activation as the only determinant of fear responding. Neuroscience \& Biobehavioral Reviews, 112, 410-419.

Borsboom, D., Cramer, A. O., \& Kalis, A. (2019). Brain disorders? Not really: Why network structures block reductionism in psychopathology research. Behavioral and Brain Sciences.

Bregman, E. O. (1934). An attempt to modify the emotional attitudes of infants by the conditioned response technique. The Pedagogical Seminary and Journal of Genetic Psychology, 45, 169-198.

Bouton, M. E. (2002). Context, ambiguity, and unlearning: sources of relapse after behavioral extinction. Biological Psychiatry, 52, 976-986.

Chalkia, A., Schroyens, N., Leng, L., Vanhasbroeck, N., Zenses, A. K., Van Oudenhove, L., \& Beckers, T. (2020). No persistent attenuation of fear memories in humans: A registered replication of the reactivation-extinction effect. Cortex, 129, 496-509.

Chalkia, A., Weermeijer, J., Van Oudenhove, L., \& Beckers, T. (2019). Acute but not permanent effects of propranolol on fear memory expression in humans. Frontiers in Human Neuroscience, 13, e51.

Chen, J. Y., \& Hou, J. L. (2018). Controllable synthetic ion channels. Organic Chemistry Frontiers, 5(10), 1728-1736.

Cook, S. A., \& Harris, R. E. (1937). The verbal conditioning of the galvanic skin reflex. Journal of Experimental Psychology, 21, 202-2010. 
Darwin, C. (1872). The expression of the emotions in man and animals. London: John Murray.

THIS ISSUE: De Houwer, J. (2020). Revisiting classical conditioning as a model for anxiety disorders: A conceptual analysis and brief review. Behaviour Research and Therapy.

De Houwer, J., \& Hughes, S. (2020). The psychology of learning: An introduction from a functional-cognitive perspective. Cambridge, MA: MIT Press.

Digdon, N., Powell, R. A., \& Harris, B. (2014). Little Albert's alleged neurological impairment: Watson, Rayner, and historical revision. History of Psychology, 17(4), 312324.

Dunsmoor, J. E., Kroes, M. C., Braren, S. H., \& Phelps, E. A. (2017). Threat intensity widens fear generalization gradients. Behavioral neuroscience, 131(2), 168.

Eelen, P., \& Vervliet, B. (2006). Fear Conditioning and Clinical Implications: What Can We Learn From the Past? In M. G. Craske, D. Hermans, \& D. Vansteenwegen (Eds.), Fear and learning: From basic processes to clinical implications (pp. 17-35). American Psychological Association.

English, H. B. (1929). Three cases of the "conditioned fear response.". The Journal of Abnormal and Social Psychology, 24, 221-225.

THIS ISSUE: Esser, R., Fuss, J., \& Haaker, J. (2020). Initial evidence for pharmacological modulation of observational threat learning by the GABAergic, but not the noradrenergic system in humans. Behaviour Research and Therapy.

Field, A. P., \& Nightingale, Z. C. (2009). Test of time: What if little albert had escaped?. Clinical Child Psychology and Psychiatry, 14, 311-319.

THIS ISSUE: Fullana, M. A., Dunsmoor, J. E., Schruers, K. R. J., Savage, H. S., Bach, D. R., \& Harrison, B. J. (2020). Human fear conditioning: From neuroscience to the clinic. Behaviour research and therapy. 
THIS ISSUE: Hammell, A. E., Helwig, N. E., Kaczkurkin, A. N., Sponheim, S. R., \& Lissek, S. (2020). The temporal course of over-generalized conditioned threat expectancies in posttraumatic stress disorder. Behaviour research and therapy.

Haselgrove (2016). Overcoming associative learning. Journal of Comparative Psychology, 130, $226-240$.

Hermans, D., Boddez, Y., \& Vervliet, B. (2019). The experimental study of mental health problems: building on Watson and Rayner (1920). In G. C. L. Davey (Ed.) Clinical Psychology: Revisiting the Classic Studies, pp. 27-40. London: Sage Publications.

Holland, P. C. (1993). Cognitive aspects of classical conditioning. Current opinion in neurobiology, 3, 230-236.

Honey, R. C., Dwyer, D. M., \& Iliescu, A. F. (2020). HeiDI: A model for Pavlovian learning and performance with reciprocal associations. Psychological Review.

Hopkins, E. J., Weisberg, D. S., \& Taylor, J. C. (2016). The seductive allure is a reductive allure: People prefer scientific explanations that contain logically irrelevant reductive information. Cognition, 155, 67-76.

Hovland, C. I. (1937a). The generalization of conditioned responses: I. The sensory generalization of conditioned responses with varying frequencies of tone. The Journal of General Psychology, 17, 125-148.

Hovland, C. I. (1937b). The generalization of conditioned responses: II. The sensory generalization of conditioned responses with varying intensities of tone. The Pedagogical Seminary and Journal of Genetic Psychology, 51(2), 279-291.

Hovland, C. I. (1937c). The generalization of conditioned responses. III. Extinction, spontaneous recovery, and disinhibition of conditioned and of generalized responses. Journal of Experimental Psychology, 21(1), 47. 
Hovland, C. I. (1937d). The generalization of conditioned responses. IV. The effects of varying amounts of reinforcement upon the degree of generalization of conditioned responses. Journal of Experimental Psychology, 21(3), 261.

Hull, C. L. (1943). Principles of behavior. New York: Appleton-century-crofts.

Hull, C. L. (1947). The problem of primary stimulus generalization. Psychological Review, 54, 120-134.

Hunt, C., Cooper, S. E., Hartnell, M. P., \& Lissek, S. (2019). Anxiety sensitivity and intolerance of uncertainty facilitate associations between generalized Pavlovian fear and maladaptive avoidance decisions. Journal of abnormal psychology, 128(4), 315-326.

Jones, M. C. (1924a). A laboratory study of fear: The case of Peter. The Journal of Genetic Psychology, 31, 308-315.

Jones, M. C. (1924b). The elimination of children's fears. Journal of Experimental Psychology, 7, 382-390.

Jones, H. E. (1928). Conditioned pyschologalvanic responses in infants. Psychological Bulletin, 25, 183-184.

Jones, H. E. (1930). The retention of conditioned emotional reactions in infancy. The Pedagogical Seminary and Journal of Genetic Psychology, 37, 485-498.

Jones, H. E. (1931). The conditioning of overt emotional responses. Journal of Educational Psychology, 22, 127-130.

Jozefowiez, J. (2018). Associative versus predictive processes in Pavlovian conditioning. Behavioural processes, 154, 21-26.

THIS ISSUE: Keller, N. E., Hennings, A. C., \& Dunsmoor, J. E. (2020). Behavioral and neural processes in counterconditioning: Past and future directions. Behaviour Research and Therapy. 
THIS ISSUE: Klein, Z., Shner, G., Ginat-Frolich, R., Vervliet, B., \& Shechner, T. (2020). The effects of age and trait anxiety on avoidance learning and its generalization. Behaviour Research and Therapy.

Krakauer, J. W., Ghazanfar, A. A., Gomez-Marin, A., MacIver, M. A., \& Poeppel, D. (2017). Neuroscience needs behavior: correcting a reductionist bias. Neuron, 93, 480-490.

Lange, J., Dalege, J., Borsboom, D., van Kleef, G. A., \& Fischer, A. H. (2020). Toward an Integrative Psychometric Model of Emotions. Perspectives on Psychological Science, 15, 444-468.

Lashley, K. S., \& Wade, M. (1946). The Pavlovian theory of generalization. Psychological Review, 53, 72-87.

LeDoux, J. (2003). The emotional brain, fear, and the amygdala. Cellular and Molecular Neurobiology, 23, 727-738.

THIS ISSUE: Lipp, O. V., Waters, A. M., Luck, C. C., Ryan, K. M., \& Craske, M. G. (2020). Novel approaches for strengthening human fear extinction: The roles of novelty, additional USs, and additional GSs. Behaviour Research and Therapy.

Lommen, M. J., Engelhard, I. M., Sijbrandij, M., van den Hout, M. A., \& Hermans, D. (2013). Pre-trauma individual differences in extinction learning predict posttraumatic stress. Behaviour research and therapy, 51(2), 63-67.

Mertens, G., Boddez, Y., Sevenster, D., Engelhard, I. M., \& De Houwer, J. (2018). A review on the effects of verbal instructions in human fear conditioning: Empirical findings, theoretical considerations, and future directions. Biological Psychology, 137, 49-64.

Mertens, G., \& Engelhard, I. M. (2020). A systematic review and meta-analysis of the evidence for unaware fear conditioning. Neuroscience and Biobehavioral Reviews, 108, 254-268. 
THIS ISSUE: Mertens, G., Krypotos, A. M., \& Engelhard, I. M. (2020). A review on mental imagery in fear conditioning research 100 years since the 'Little Albert'study. Behaviour Research and Therapy.

THIS ISSUE: Meulders, A. (2020). Fear in the context of pain: Lessons learned from 100 years of fear conditioning research. Behaviour Research and Therapy.

Milad, M. R., \& Quirk, G. J. (2012). Fear extinction as a model for translational neuroscience: ten years of progress. Annual Review of Psychology, 63, 129-151.

Miller, R. R., Barnet, R. C., \& Grahame, N. J. (1995). Assessment of the Rescorla-Wagner model. Psychological bulletin, 117(3), 363-383.

Mineka, S., \& Zinbarg, R. (2006). A contemporary learning theory perspective on the etiology of anxiety disorders: it's not what you thought it was. American psychologist, 61(1), 10-26.

Mitchell, C. J., De Houwer, J., \& Lovibond, P. F. (2009). The propositional nature of human associative learning. Behavioral and Brain Sciences, 32, 183-198.

Moors, A. (2017). Integration of two skeptical emotion theories: Dimensional appraisal theory and Russell's psychological construction theory. Psychological Inquiry, 28(1), 1-19.

Moors, A., Boddez, Y., \& De Houwer, J. (2017). The power of goal-directed processes in the causation of emotional and other actions. Emotion Review, 9(4), 310-318.

Moss, F. A. (1924). Note on Building Likes and Dislikes in Children. Journal of Experimental Psychology, 7, 475-478.

Öhman, A., \& Mineka, S. (2001). Fears, phobias, and preparedness: Toward an evolved module of fear and fear learning. Psychological Review, 108, 483-522.

Pavlov, I. P. (1906). The Huxley lecture on the scientific investigation of the psychical faculties or processes in the higher animals. The Lancet, 168, 911-915. 
Pavlov, I. P. (1927). Conditioned Reflexes: An Investigation of the Physiological Activity of the Cerebral Cortex. Oxford University Press, London, 1927.

THIS ISSUE: Peyrot, C., Brouillard, A., Morand-Beaulieu, S., \& Marin, M. F. (2020). A review on how stress modulates fear conditioning: Let's not forget the role of sex and sex hormones. Behaviour Research and Therapy.

THIS ISSUE: Pittig, A., Wong, A. H., Glück, V. M., \& Boschet, J. M. (2020). Avoidance and its bi-directional relationship with conditioned fear: Mechanisms, moderators, and clinical implications. Behaviour Research and Therapy.

THIS ISSUE: Pöhlchen, D., Leuchs, L., Binder, F. P., Blaskovich, B., Nantawisarakul, T., Topalidis, P., ... \& Czisch, M. (2020). No robust differences in fear conditioning between patients with fear-related disorders and healthy controls. Behaviour Research and Therapy.

Powell, R. A., Digdon, N., Harris, B., \& Smithson, C. (2014). Correcting the record on Watson, Rayner, and Little Albert: Albert Barger as “Psychology's lost boy”. American Psychologist, 69(6), 600-611.

Rachman, S. J. (1977). The conditioning theory of fear acquisition: A critical examination. Behaviour Research and Therapy, 15, 375-387. doi:10.1016/0005-7967(77)90041-9

Rescorla, R. A., \& Wagner, A. R. (1972). A theory of Pavlovian conditioning: Variations in the effectiveness of reinforcement and nonreinforcement. In A. H. Black \& W. F. Prokasy (Eds.), Classical conditioning II: Current research and theory (pp. 64-99). New York: Appleton-Century-Crofts.

Scheveneels, S., Boddez, Y., \& Hermans, D. (2019). Learning mechanisms in fear and anxiety: It is still not what you think it is. In B. O. Olatunji (Ed.), The Cambridge handbook of anxiety and related disorders (pp. 13-40). Cambridge: Cambridge University Press. 
Scheveneels, S., Boddez, Y., Vervliet, B., \& Hermans, D. (2016). The validity of laboratorybased treatment research: Bridging the gap between fear extinction and exposure treatment. Behaviour Research and Therapy, 86, 87-94.

Singewald, N., Schmuckermair, C., Whittle, N., Holmes, A., \& Ressler, K. J. (2015). Pharmacology of cognitive enhancers for exposure-based therapy of fear, anxiety and trauma-related disorders. Pharmacology \& Therapeutics, 149, 150-190.

Skinner, B. F. (1953). Science and human behavior. Macmillan.

Skinner, B.F., 1977. Why I am not a cognitive psychologist. Behaviorism 5, 1-10.

Todes, D. P. (2014). Ivan Pavlov: A Russian life in science. Oxford University Press, USA.

Vervliet, B., \& Boddez, Y. (2020). Aversive stimulus pairings are an unnecessary and insufficient cause of pathological anxiety. Biological Psychiatry.

Vervliet, B., \& Raes, F. (2013). Criteria of validity in experimental psychopathology: application to models of anxiety and depression. Psychological medicine, 43(11), 22412244.

Weisberg, M. (2013). Simulation and Similarity: Using models to understand the world. Oxford University Press: Oxford

Weisberg, D. S., Keil, F. C., Goodstein, J., Rawson, E., \& Gray, J. R. (2008). The seductive allure of neuroscience explanations. Journal of Cognitive Neuroscience, 20, 470-477.

Switzer, C. A. (1933). Disinhibition of the conditioned galvanic skin response. The Journal of General Psychology, 9, 77-100.

Thorndike, E. L. (1913). Educational psychology, Vol. 1. The original nature of man. Teachers College.

Vansteenwegen, D., Hermans, D., Vervliet, B., Francken, G., Beckers, T., Baeyens, F., \& Eelen, P. (2005). Return of fear in a human differential conditioning paradigm caused by a return to the original acquistion context. Behaviour Research and Therapy, 43, 323-336. 
Vervliet, B., \& Boddez, Y. (2020). Commentary: Aversive stimulus pairings are an unnecessary and insufficient cause of pathological anxiety. Biological Psychiatry, 87, 870-871.

Watson, J. B. (1913). Psychology as the behaviorist views it. Psychological review, 20, 158177.

Watson, J. B. (1916). The place of the conditioned reflex in psychology. Psychological Review, 23, 89-116.

Watson, J. B. (1924). Behaviorism. New York: People’s institute.

Watson, J. B., \& Morgan, J. J. B. (1917). Emotional reactions and psychological experimentation. The American Journal of Psychology, 28, 163-174.

Watson, J. B., \& Rayner, R. (1920). Conditioned emotional reactions. Journal of Experimental Psychology, 3, 1-14.

Watson, J. B., \& Rayner, R. (1921). Studies in infant psychology. The Scientific Monthly, 13, 493-515.

Zenses, A.-K., Baeyens, F., Beckers, T., \& Boddez, Y. (2020). Thought conditioning: Inducing and reducing thoughts about the aversive outcome in a fear conditioning procedure. Clinical Psychological Science. 


\section{Footnotes}

${ }^{1}$ Watson, Rayner and contemporaries ordinarily used the terms 'conditioned' and 'unconditioned' to denote the different stimuli and responses in the conditioning situation. However, it has been noted that this is an inaccurate translation from the original Russian text (Todes, 2014). The correct translation would have been 'conditional' and 'unconditional', which captures more directly the core observation in conditioning: A stimulus comes to elicit a response conditionally upon its having been paired with a stimulus that unconditionally elicits a given response. For correctness, we use the terms 'conditional' and 'unconditional' throughout, except in citations and in direct references to titles of papers.

${ }^{2}$ For more background information on the Little Albert study and on the life story of its participant, we refer the interested reader to Beck, Levinson, and Irons (2009), Digdon, Powell, and Harris (2014), Eelen and Vervliet (2006), Field and Nightingale (2009), Hermans, Boddez, and Vervliet (2019), Powell, Digdon, Harris, and Smithson (2014).

${ }^{3}$ It is of note that the term model may serve to highlight that one can also pragmatically consider the association formation model to be just one possible analogue that can help us to organize or gain knowledge about behavior (i.e., the target). As such, the association formation model does not necessarily have to - and is even unlikely to - correspond to what it is actually like in the mind (Boddez, Moors, Mertens, \& De Houwer, 2020). This idea of the association formation model as an analogue might perhaps be easier to grasp if one considers that one could also realize such model physically (e.g., an actual landscape with neon signs that are connected with copper wires) rather than verbally (i.e., how they are typically presented in papers and textbooks; Weisberg, 2013), just as one can build physical models (e.g., different synthetic ion channels) of a physical phenomenon (e.g., natural ion 
channels). Even if the workings of such physical model do not fully correspond to the workings of the mind, it may still help us organize and gain knowledge about behavior (in the same way as a metaphor - or indeed an "analogy" - could). 